\title{
The Liverpool Meeting of the British Association.
}

\section{I.-Local Arrangements.}

THE preliminary programme and invitation circular for the meeting at Liverpool of the British Association in September has recently been issued, and the subjects of the various presidential addresses and the chief sectional discussions have been mentioned in NATURE for June $x 6, p .825$. A short account of the local arrangements may, however, be of interest to members of the Association who intend coming to Liverpool, as well as to others who are as yet undecided about their attendance at the meeting.

The Reception Room and the General Offices will be at St. George's Hall, though accommodation will also be provided at the University for meeting rooms, etc., for offices and members if required. St. Greorge's Hall, though rather more than half a mile from the University, where very many of the sections will hold their meetings, is admirably situated in the centre of the city, close to the railway stations and easily accessible by tram from all parts. The experience of the last meeting showed how excellent a reception room it proved, while its beautiful tessellated floor adds a decorative value most reception rooms lack.

Section E (Geography), and Section F (Economics) will meet in St. George's Hall, the former in the concert room and the latter in one of the large rooms used ordinarily for purposes of the assizes. These rooms being in the same building as the Reception Room itself could not be more convenient. Section $\mathrm{H}$ (Anthropology) will meet in the lecture theatre belonging to the Public Museum, not more than a few minutes' walk from the Reception Room. The other sections will all meet in the University buildings. For convenience of getting to and fro between the Reception Room and the University, it is proposed to run a service of motor buses.

The inaugural meeting and presidential address, as well as the evening lecture by Prof. Elliot Smith, will be held in the Philharmonic Hall, which has a seating capacity of about 3000 . Citizens' lectures will be given in the Picton Hall, Liverpool, as well as in several of the neighbouring boroughs, and it is also intended to give a few lectures to young people, as these proved such a great success at last year's meeting at Hull.

The Lord Mayor is giving a reception to members of the Association in the Walker Art Gallery and Museum and Library (all three buildings being " en suite ") on Thursday evening, September r3, and for that occasion it has been arranged to exhibit the greater portion of the permanent art collections of the city as well as to show exhibits of interest in the Library and Museum.

On the last evening of the meeting, Tuesday September 18 , a scientific soirée will be held at the University. This gathering, based on the lines of the Royal Society functions, will, it is believed, be of the greatest interest, as a very large number of exhibits and experiments illustrating recent developments in science will be on view. There will also be a series of lecturettes by eminent men of science. It may be mentioned that the committee engaged in the organisation of this soirée at the University hope that as many members of the Association as possible will wear full academic dress on that occasion.

During the whole of the meeting, an exhibition of scientific apparatus, specimens, diagrams, etc., representative of the work of all the thirteen sections of the Association, will be on view in the Central Technical School, kindly placed at the disposal of the local committee by the Technical and Commercial Education Sub-Committee of the Corporation. This exhibition should prove of interest to all members, if one may judge from the small sectional exhibits which have been features of the Association meetings on several occasions during the last decade. All members of the Association will be admitted free.

A comprehensive series of excursions and visits to works and places of interest in the neighbourhood is being arranged, and the local committee hope the programme will provide interest for all

A special handbook is in preparation. It will contain a number of articles dealing with the whole district of which Liverpool is the centre, rather than being restricted to the city and its immediate environs. It is hoped members will find it of more than merely ephemeral interest, as the articles are all by authors well qualified to write on their particular subjects.

Every effort is being made by the local committee to make the meeting a signal success. It is hoped very much that all those interested in science, even if not actually professional scientific workers, will attend. The local programme is developing week by week, and there is no doubt that by the date the meeting commences, provision will have been made for every minute of the member's day. ALFRED HolT.

\section{The Thunderstorm of July 9-Io over Southern England.}

THE thunderstorm which visited London during the night of July $9-$-Io will find a place on the list of famous storms rather for its duration and for the spectacular effect produced at night by the incessant lightning, than for the quantity of rain associated with it or the damage done, though neither of these was by any means negligible. It is too early yet to attempt anything like a complete account of the storm, but data already at hand, and personal observations generously placed at my disposal, render a preliminary note possible.

Apart from the long duration, the most noteworthy general characteristics appear to have been the sudden development with little in the way of sky signs to aid the isolated observer, the general lack of hail, the absence of any marked squalls of wind at the surface, and the very marked preponderance of cloud-to-cloud discharges, without which the damage might have been very much worse.

The storm ${ }^{x}$ first made its appearance about 8.30 P.M. (Greenwich time) on the south coast, where it was seen approaching from the south-east. . It then progressed N.N.W., in the direction of London, where a corresponding phase was reached about two hours later, the system having advanced at a speed of roughly 25 miles per hour. This rate of movement appears to have been maintained in the same direction across Bedford and Peterborough, and then, rather faster, on to Hull and Middlesbrough. Thunderstorms which occurred later on July Io at Berwick,

The disturbance as a whole is referred to as the storm, but the system undoubtedly had several nuclei.

NO. 280.3 , VOL. I I 27 
Aberdeen and in the Shetlands, all on the continuation of this line, were not improbably related to the same general cause, though the continuity of the advance of the original system cannot be verified.

The main rainfall was confined to a belt between 30 and 40 miles in width, lying along the track of the storm. In this zone, falls were probably everywhere greater than $I$ in., at least as far north as the Wash, while they equalled 2 in. in many places, and reached 3 in. in isolated patches. On the south coast this belt of heavy rain extended from a point between Worthing and Brighton to a point between Eastbourne and Hastings, while central London lay in the middle of the affected zone. Outside this band, amounts fell off quickly, particularly on the eastern side, where the boundary was sharply defined; for example, while Eastbourne received $\mathrm{I}_{\frac{3}{4}}$ in., Hastings and places further east escaped rain, and while Tunbridge Wells experienced nearly an inch, there was none at Maidstone.

Over the southern portion of the track, including London, rain fell practically continuously for more than 6 hours, so that, allowing the speed of 25 miles per hour, the main travelling rain system responsible for this belt of precipitation was here probably about I 50 miles long in the direction of its motion, and 35 miles broad.

In the north, the amounts and duration of rainfall appear to have been rather less than in the south of England.

Striking agreement in time is shown by the hyetograph and microbarograph records at South Kensington between sudden changes of pressure and intense bursts of rain, particularly just after 2 A.M. (G.M.T.). There is also agreement between the sudden changes of pressure at South Kensington and those recorded at Kingsway, London, W.C.2, by the Dines float barograph, which shows the absolute magnitude of the pressure changes. It is interesting to mention that an observer in Hampstead noted quite independently that the worst crashes, followed immediately by torrential rain, occurred at 2.I5 A.M. and 3.45 A.M. (G.M.T.). The first of these was about ro minutes after the occurrence of the very pronounced peak in the Kensington microbarograph record and corresponding heavy rain shown by the hyetograph record. Thus, allowing 4 miles between the places of observation, we again find phenomena associated with the storm travelling at about 25 miles per hour.

Although a closer investigation is desirable before putting forward an explanation of the storm with full confidence, an examination of the weather charts and upper air data available brings to light some very suggestive facts. Measurements of upper winds on the evening before the storm show that between about 6000 feet and 18,000 feet above the surface there was a general wind current over the affected area agreeing very closely indeed in direction and speed with those of the movement of disturbance itself, and observations of the drift of cirrus cloud show that above this the air motion was probably from about S.W. Now the weather charts for July 8 and 9 show an anticyclone over the Continent and a depression almost stationary off the West of Ireland, and, further, a current of air of undoubtedly polar origin, and therefore probably having a low upper-air temperature, circulating round the latter.

It seems very likely that some of this polar air, in arriving, at some upper level, over the south-west districts of England and endeavouring to work its way northwards, side by side with the very warm air of continental origin over the eastern districts, spread laterally over the latter, producing the travelling area of instability necessary to explain the phenomena described above.
M. A. GibletT.

\section{The Pascal Commemoration on the Puy de Dôme.}

TH IE tercentenary of the birth of Blaise Pascal (born June 19, 1623, died August 19, I662) was celebrated at Clermont-Ferrand in a series of fêtes at which the President of the French Republic, M. Millerand, and the most distinguished French scholars and philosophers met to do homage to his great genius.

The culminating interest of the celebrations was the visit to the summit of the Puy de Dôme on Sunday, July 8 , to commemorate the experiment devised by Pascal and carried out successfully by his brother-in-law Florin Périer, an experiment as famous in its day and as decisive in its significance as the eclipse expedition of May I9r9 has proved to be in our day. In demonstrating that the atmosphere has weight it destroyed a principle of the old physics which had become authoritative, the principle that Nature abhors a vacuum, and at the same time it inaugurated a new scientific concept in physics. The rain poured as we gathered on the summit where, above the ruins of an ancient temple of Mercury, a modern meteorological observatory has been erected. Those who were so fortunate as to find room in the small cupola of the observatory, however, are not likely to forget M. Painlevé's discourse. Round the President were grouped the Prefects of the Departments, the Mayor of Clermont, the Rector of the University, Senators and Deputies, the representatives of the Institut de France, and the foreign guests of the Municipality. In an eloquent oration M. Painlevé described the inception of the great experiment and discussed its significance.
No one of that large company (the Municipality entertained three hundred guests at the déjeuner on the mountain) who had ascended the mountain by the modern means of electric traction with luxurious comfort in little more than an hour can have failed to reflect on the different conditions which prevailed in Pascal's time, and on the enormous difficulties of the original expedition. Those who are interested may read the full and careful report of it in Périer's letter to Pascal. It was arranged that first of all two sets of apparatus should be tested side by side to see that they gave identical measurements, that is, to see that each column of mercury in the inverted tubes (barometer tubes) remained at the same height. One set was then carried up to the top of the mountain and the other left behind in the church of the Minimes at Clermont. The experiments with each set were made at the prearranged hour and precisely recorded. The significance of the experiment was its uniqueness. It differed entirely from observations which any one might make with the scientific intention of recording facts; it differed entirely, for example, from observations such as those of Tycho Brahe. It was uniquely designed to test a physical theory which would stand or fall by the result. It had been known practically by engineers for a long time that there was a natural limit to the action of a pump, and in the crucial experiment of Torricelli with the column of mercury in the glass tube closed at one end and immersed in liquid at the other it was shown that the principle was

No. 2803 , vOL. I I 27 